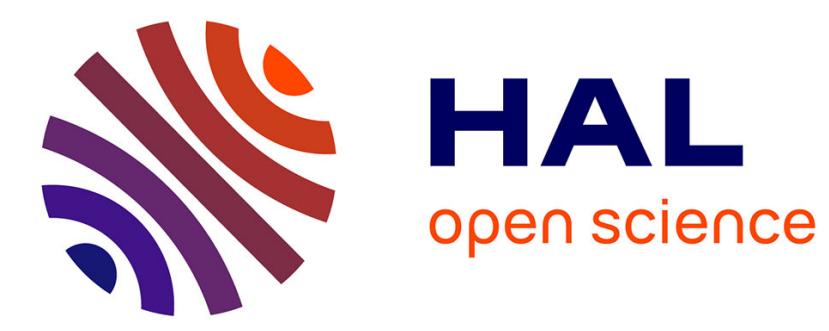

\title{
Cold-spray ionization mass spectrometry of the choline chloride-urea deep eutectic solvent (reline)
}

Lucie Percevault, Thomas Delhaye, Alain Chaumont, Rachel Schurhammer, Ludovic Paquin, David Rondeau

\section{- To cite this version:}

Lucie Percevault, Thomas Delhaye, Alain Chaumont, Rachel Schurhammer, Ludovic Paquin, et al.. Cold-spray ionization mass spectrometry of the choline chloride-urea deep eutectic solvent (reline). Journal of Mass Spectrometry, 2021, 56 (5), pp.e4725. 10.1002/jms.4725 . hal-03223162

\section{HAL Id: hal-03223162 https://hal.science/hal-03223162}

Submitted on 21 Jun 2021

HAL is a multi-disciplinary open access archive for the deposit and dissemination of scientific research documents, whether they are published or not. The documents may come from teaching and research institutions in France or abroad, or from public or private research centers.
L'archive ouverte pluridisciplinaire HAL, est destinée au dépôt et à la diffusion de documents scientifiques de niveau recherche, publiés ou non, émanant des établissements d'enseignement et de recherche français ou étrangers, des laboratoires publics ou privés. 


\title{
Cold-Spray Ionization Mass Spectrometry of the Choline Chloride-Urea Deep Eutectic Solvent (Reline)
}

Lucie Percevault, ${ }^{1}$ Thomas Delhaye, ${ }^{2}$ Alain Chaumont, ${ }^{3}$ Rachel Schurhammer, ${ }^{3}$ Ludovic Paquin $^{1}$ and David Rondeau ${ }^{2,4}$

1. Université de Rennes 1, CNRS ISCR (Institut des Sciences Chimiques de Rennes) (UMR CNRS 6226), Campus de Beaulieu, 263 avenue du Général Leclerc, Rennes Cedex 35042, France.

2. Université de Rennes 1, CNRS IETR (Institut d'Electronique et des Technologies du numéRique (UMR CNRS 6164), Campus de Beaulieu, 263 avenue du Général Leclerc, Rennes Cedex 35042, France.

3. Université de Strasbourg, CNRS CMC UMR 7140, Laboratoire MSM, 4 rue Blaise Pascal F-67000 Strasbourg, France

4. Université de Bretagne Occidentale, Département de Chimie, 6 avenue Le Gorgeu, 29238, Brest, France.

\begin{abstract}
Cold-Spray Ionization mass spectrometry (CSI-MS) that can be compared to an electrospray ionization (ESI) source acting with a nebulizing gas cooled by liquid nitrogen, is used for analysing reline as Deep Eutectic Solvent (DES). The association of cholinium chloride salts with urea molecules is evidenced in negative CSI-MS through the chloride adduct formation. The structure of the supramolecular assemblies forming the reline ions that are observed on CSI mass spectra, is rationalized by chemical quantum calculation. The theoretical studies indicate that the ionic network organisation is only supported by a maximization of hydrogen bonds of the chlorides with the hydroxyl and methyl moieties of the cholinium cations and the amino groups of urea. The studies of gas-phase fragmentation of the supra-molecular ionic assemblies detected in CSI-MS are performed using the in-source collision induced dissociation experiments. The experimental measurements in CSI-MS, interpreted at the light

This article has been accepted for publication and undergone full peer review but has not been through the copyediting, typesetting, pagination and proofreading process which may lead to differences between this version and the Version of Record. Please cite this article as doi: $10.1002 / j m s .4725$
\end{abstract}


of the molecular modelisation results suggest that the insertion of urea in adducts of chlorides with cholinium cations do not lead to the most stable ions.

Keywords: Cold-Spray Ionization, Deep Eutectic Solvent, Reline, Chemical Quantum Calculation, In-Source CID.

\section{Introduction}

Deep eutectic solvents (DESs) can be defined either as low-melting-temperature mixture with at least one salt as component or as a mixture of Lewis or Brønsted acids and bases that can contain a variety of species yielding an eutectic with a melting point much lower than each of components. This new generation of green solvents, described for the first time by Abbott et al. in $2003,{ }^{1}$ are known for their low toxicity, non-volatility and low production cost. Their organization is based on associations between a hydrogen bond acceptor (HBA) such as an ammonium halide and an hydrogen-bond donor (HBD). ${ }^{2,3}$ The possibility to substitute organic solvents and ionic liquids by DESs has been described in various application fields of chemistry such as extraction, synthesis, catalysis, carbon dioxide capture or electrochemistry. ${ }^{3-13}$ In order to better rationalize the DES molecular organization, theoretical and experimental studies have been performed by focussing on reline so-known as archetypical DES. Reline is a blend of choline chloride salt $(\mathrm{ChCl})$ and urea molecule (U) (see Scheme 1) in molar ratio 1:2. The use of spectroscopic methods (RMN and IR), ${ }^{14-17}$ the analysis of Inelastic Neutron Scattering (INS) spectra together with the results of ab initio quantum chemical calculations and molecular dynamic simulations, have allowed to propose two main organization modes. ${ }^{18-23}$ The associations of the reline constituents are then described through the optimization of the hydrogen bonds as the urea molecules get into the H-bond network initially formed by the interactions between the cholinium cations and the chloride anions. The HBD properties of the cholinium are due either to its hydroxyl moieties and the $\mathrm{C}-\mathrm{H}$ bonds of their methyl groups while chloride is the HBA compound. In this model, the urea contributes to the DES organization first by disrupting this pre-existent network, then by maximizing the hydrogen bonds through the HBD character of their amino groups. ${ }^{17,19,21,22}$ Another organization mode proposes that ionic interactions could participate to the non-covalent stable complex assembly. ${ }^{18}$ In this case, the DES organization is ensured by the HBD character of urea molecule interacting with a chloride anion whereas the free rotor hydroxyl group of a choline maintains a strong hydrogen bond with this chloride whilst maximizing its interaction with urea 
through Coulomb attractions between its ammonium and the carbonyl oxygen of urea. All these spectroscopic measurements and the associated theoretical studies, suggest that the H-bonds or the charge delocalization could be at the origin of a sandwich structure where each chloride would be in interaction with one choline cation and two urea molecules. This behavior described through analyses realized on DES models in condensed phase, should be completed by studies on the intrinsic stability of the basic structure assumed as being at the origin of the DES organization.

In this context, for attempting to better understand DES molecular organization, we have applied the Cold-Spray Ionization (CSI) Mass Spectrometry (MS) to reline analysis, together with quantum mechanical calculations to investigate in detail the interactions involved in the non-covalent associations disclosed by the interpretation of CSI mass spectra. Cold-spray ionization also called as cryo-spray is a low-temperature variant of electrospray ionization (ESI) that was developed for characterizing labile non-covalent complexes that cannot be observed by conventional mass spectrometry techniques. ${ }^{24,25}$ The CSI method can be described as an ESI source where the sprayer is a probe submitted to a coaxial nebulizing gas cooled by a liquid nitrogen device maintaining the temperature of the capillary below $-30{ }^{\circ} \mathrm{C} .{ }^{26} \mathrm{In} \mathrm{CSI}$, the shrinkage and the fissions of charged droplets are not thermally assisted in the desolvation chamber as in ESI. The ionization mechanism and the desolvation process are rather ensured by an increasing of the medium dielectric polarization $(\mathrm{P})$ at low temperature, where: $\mathrm{P}=\varepsilon_{r}\left(\varepsilon_{0}\right.$ - 1)E, with $\varepsilon_{r}$ is the relative permittivity and the strong electric field (E) at the surface of the charged micro-droplets and $\varepsilon_{0}$ is the vacuum permittivity. ${ }^{25}$ This increased polarizability of the solvent molecules induced by the high values of $\varepsilon_{r}$ at low temperature favours charge separations in the solution emerging from the capillary tip and leads to observe free-solvent gaseous "brittle" ionic species. ${ }^{27}$ The CSI method has been namely used for characterizing the structures of labile inorganic and organometallic compounds in solution or investigating labile solution structures of biomolecules such as DNA. ${ }^{28-31}$ The use of CSI-MS analysis in coordination chemistry allows for discriminating between no-covalent complexes in solution whether they are discrete or oligomeric coordination species. ${ }^{32-34}$ It has also been shown that CSI mass spectrometry as NMR spectroscopy and X-ray crystallography, allows to study the formation of large-scale aggregated chain structures or clusters in solution through intermolecular hydrogen bonds. ${ }^{35}$

To our knowledge, the cold-spray ionization mass spectrometry has never been used to disclose no-covalent structures that can characterize a DES such as reline. The new experimental data 
that are obtained from this work have been interpreted to the light of theoretical studies in order to complete the data already compiled from other spectroscopic methods and to bring additional criterions of rationalization of the DES organization.

\section{Experimental}

\subsection{Chemical}

The chemicals used for the preparation of the DES, choline chloride $(\geq 99 \%)$ and urea $(\geq$ 99.5\%) were supplied by Acros Organics and used without further purification. UPLC/MS grade acetonitrile was purchased from Biosolve Chimie (Dieuze, France).

\subsection{Preparation}

Deep eutectic solvent reline was prepared by mixing choline chloride and urea in a molar ration $1: 2$ at $80^{\circ} \mathrm{C}$ under stirring for $4 \mathrm{~h}$ until an homogeneous and transparent liquid was obtained. The DES was allowed to cool at room temperature and stored. The DES solution was diluted in pure acetonitrile at $0.5 \%(\mathrm{v}: \mathrm{v})$ and stored at room temperature for the ESI and CSI analyses.

\subsection{Mass Spectrometry}

Cold-Spray Ionization (CSI) and Electrospray Ionization (ESI) mass spectra were acquired using an AccuTOF CS mass spectrometer (JEOL,Tokyo, Japan). The scheme depicted in Figure 1, illustrates the different items of this dual ESI/CSI source. The needle voltage was set at $-1.5 \mathrm{kV}$. Nitrogen was used as nebulizer and dry gas at flow rates of 1.0 and $2.0 \mathrm{~L} / \mathrm{min}$, respectively. The nebulizer gas temperature was set between -40 and $0{ }^{\circ} \mathrm{C}$ depending of the performed CSI-MS experiments with a desolvation chamber that does not exceed $30^{\circ} \mathrm{C}$. For conventional ESI-MS, the desolvation chamber temperature was set at $230^{\circ} \mathrm{C}$ with a nebulizer gas that was introduced at room temperature. Unless indication mentioned in the text or in the figure captions, the voltages of the Orifices 1 and 2 lenses were generally set at 30 and $-5 \mathrm{~V}$, respectively. The Ring Lens voltage was set at $-15 \mathrm{~V}$. The bias voltage of the Ion Guide has been set at $-29 \mathrm{~V}$. The Ion Guide peak voltage was fixed at $1100 \mathrm{~V}$. The detector voltage was set at $2300 \mathrm{~V}$. It can be noted that the value read for the Orifice 2 voltage, corresponds in fact to the potential difference, so-called OR2 in Figure 1, between this lens and the bias voltage applied on the Ion Guide. Then, the value read for the Orifice 1 voltage, represents the potential difference, so-called OR1 in Figure 1, between this item and the voltage applied on Orifice 2. Endly, the voltage value of the Ring Lens, so-called RL in Figure 1, is the potential difference 
between this one and the Orifice 1. The mass spectra were recorded every second in the $m / z$ range 50 to 1200 and with a resolution of 6000 (fwhm definition). The mass drift compensation procedure available on the main program that controls the AccuTOF CS, was used for compensating for the $\mathrm{m} / \mathrm{z}$ drift in the range of $\mathrm{m} / \mathrm{z} 100-1100$ and performing the accurate mass measurements. The ion at $\mathrm{m} / \mathrm{z} 174.0452$ corresponding to the chloride adduct of the choline chloride dimer was selected as internal standard in negative electrospray and the ion at $\mathrm{m} / \mathrm{z}$ 155.0336 corresponding to the chloride adduct of the urea dimer was selected as internal standard in negative cold-spray.

\subsection{Chemical quantum calculations}

Stationary points were optimized with the Gaussian 09 program $^{36}$ using the B3LYP ${ }^{37}$ density functional and a 6-311++G(d,p) basis set. Dispersion corrections have been included via the D3-Grimme correction. ${ }^{38}$ This procedure is consistent with the previous work of Hunt et al. ${ }^{21}$ on similar clusters but of smaller size. All reported structures were confirmed as energy minima, with no negative eigenvalue in the Hessian matrix. Initial structures were either hand constructed or taken from molecular dynamics simulations. We simulated a box containing 100 choline chloride:urea (1:2) pairs performed with AMBER18 $8^{39}$ and the GAFF v2.11 FF Fu $^{40}$ simulated during $100 \mathrm{~ns}$. Typical arrangements with the various selected $m / z$ ratio were extracted from this simulation. Interaction energies $(\Delta \mathrm{E})$ within the different clusters were calculated as the difference between the total energy of the considered aggregate and the isolated components. Relative interaction energy for a specific conformation $\mathrm{X}\left(\Delta \mathrm{E}_{\mathrm{rel}}\right)$ is the difference, for a given $m / z$, between the energy of $X$ and the most stable one.

\section{Results and discussion}

\subsection{Cold-Spray Ionization Mass Spectrometry of reline}

The negative ion ESI and CSI mass spectra of a reline solution in acetonitrile, are reported in Figure $2 \mathrm{a}$ and $2 \mathrm{~b}$, respectively. The accurate mass measurement results and their comparison with theoretical masses calculated from elemental compositions (see Table 1) indicate that all the signals of Figure 2a correspond to chloride anion adducts with cholinium chloride units, i.e. $\left[(\mathrm{ChCl})_{n}+\mathrm{Cl}\right]^{-}$where $\mathrm{ChCl}$ is the cholinium chloride depicted in Scheme 1 and $n=2$ to 7 . The only ion population observed on the ESI(-) mass spectrum of Figure 2a, is formed by the association of a chloride with an increasing number of cholinium chloride salt. 
These results show that the ESI(-)-MS analysis do not lead for characterizing reline as a choline chloride and urea mixture, even though, in a first approximation, the species detected on the ESI mass spectrum are often characterized as the most stable assemblies emerging from charged micro-droplets. ${ }^{41,42}$ By contrast, the CSI mass spectrum of Figure $2 \mathrm{~b}$ depicts supplementary signals that disclose the presence of urea molecules in interaction with cholinium chloride salts.

This assignment is confirmed by the attributions established by accurate mass measurements and reported in Table 2. The more labile species observed in CSI-MS (see Figure $2 \mathrm{~b}$ and Table $2)$, are thus rather characteristic of reline since they are formed of two cholinum chloride $(\mathrm{ChCl})$ as salt and urea $(\mathrm{U})$ as molecule. The low temperature of the nebulizing gas of the CSI source $\left(-30^{\circ} \mathrm{C}\right.$ for the mass spectrum of Figure $\left.2 \mathrm{~b}\right)$ promotes the observation of such labile noncovalent complexes that cannot be detected in conventional ESI-MS.

More precisely, among the most abundant ions observed in CSI (see Figure 2b), the three ions $m / z, 155, m / z, 234$ and $m / z$ 373, are not detected in ESI (see Figure 2a). The $m / z, 155$ ion is the base peak in CSI-MS and corresponds to a chloride adduct with two urea molecules (see Table 2). This ion $\left[(\mathrm{U})_{2}+\mathrm{Cl}\right]^{-}$is even more abundant than the cholinium chloride ions $\left[(\mathrm{ChCl})_{n}+\mathrm{Cl}\right]^{-}$ where $n=1$ to 7 , these ones are the only ionic species emerging from the electrosprayed solution (see Figure 2a and Table 1). From their elemental composition reported in Table 2, the $m / z, 234$ and 373 ions are associations of one urea molecule (U) with one and two cholinium chloride units $(\mathrm{ChCl})$ into a chloride adduct, respectively. Note that the signals of these ions noted $\left[(\mathrm{ChCl})_{\mathrm{n}}+\mathrm{U}+\mathrm{Cl}\right]^{-}$where $n=1$ or 2 , are many more intense than the $m / z, 294$ ion $\left[(\mathrm{ChCl})_{n}+(\mathrm{U})_{m}+\mathrm{Cl}\right]^{-}$where $n=1$ and $m=2$, whereas this association of two urea molecules with one cholinium chloride has been previously pointed out as the putative basic structure in a DES organization (see Introduction). One will also remark that the relative intensity of the peaks decreases as the number of urea molecules increases in the ionic non-covalent complex observed in CSI-MS (see Table 2 and Figure 2b).

Considering that the primary difference in the step of charged micro-droplet formation between the ESI and CSI processes, is related to the spray temperature emerging from the inlet capillary tip, CSI mass spectra were performed by at -40 and $0^{\circ} \mathrm{C}$ of the nebulizing gas temperature (see Figure $3 \mathrm{a}$ and $3 b$ ).

From the mass spectra of Figure 3, the detected ions have been regrouped in four ion populations. These ones differ by the urea molecule number into the non-covalent ionic 
assemblies (see caption in Figure 3). At low temperature of the spray, i.e. $-40{ }^{\circ} \mathrm{C}$ (see Figure $3 a)$, the more intense ions are those of the population represented by the chloride adducts $\left[(\mathrm{ChCl})_{n}+\mathrm{U}+\mathrm{Cl}\right]^{-}$(where $n=1$ to 4 ). One must reach a $0^{\circ} \mathrm{C}$ spray temperature, for equalizing the intensities of these reline ions $\left[(\mathrm{ChCl})_{n}+\mathrm{U}+\mathrm{Cl}\right]^{-}$and the choline chloride adducts $\left[(\mathrm{ChCl})_{n}+\mathrm{Cl}\right]^{-}$(see the marks $\diamond$ and $\bullet$ on Figure 3 ). The mass spectra of Figure 3 and their evolution with temperature show that the increasing of the number of urea molecule in reline ions, represented by the $\left[(\mathrm{ChCl})_{n}+(\mathrm{U})_{2}+\mathrm{Cl}\right]^{-}$and $\left[(\mathrm{ChCl})_{n}+(\mathrm{U})_{3}+\mathrm{Cl}\right]^{-}$adducts (see the marks * and ${ }^{\circ}$ on Figure 3), are more intense at lower temperature, i.e. $-40^{\circ} \mathrm{C}$. They are associated to lower signal intensities and this, all the more as the spray temperature is kept at $0^{\circ} \mathrm{C}$ (see Figure 3b). These observations allow to rule out an attachment process of neutral urea that would first emitted in the gas-phase from charged droplets during the desorption step and then added to the gaseous ions in the CSI interface due to a condensation phenomenon at low temperature. This is in agreement with the ion formation mechanism described by K. Yamaguchi et al that propose in their studies in coordination chemistry that the solvent adducts observed on CSI mass spectra, represent structures established in solution rather than gas-phase additions of neutral molecules due to the low temperatures of the CSI source. ${ }^{24,25,32,33}$

In-source Collision Induced Dissociation (in-source CID) experiments have been performed by rising the voltage of the so-called Orifice 2 lens (OR2), i.e. from 2 to $15 \mathrm{~V}$, while keeping constant the so-called Orifice 1 (OR1) voltage at $30 \mathrm{~V}$. The aim of such experiments is to evaluate the relative stabilities of these ion populations by focusing on their gas-phase behavior under collision activation conditions due to the presence of residual nitrogen in this region of the mass spectrometer interface. One will note that the in-source CID experiments are usually performed by rising the Orifice 1 (OR1) voltage value. However, for the present studies it was appeared that the increasing of the OR1 voltage (with a $5 \mathrm{~V}$ fixed value for OR2) had no influence on the ion dissociation ratios such as depicted in Figure S1. By contrast whereas the increasing of the OR2 voltage value is not commonly used for such experiments, it has been observed for the present work that the ion intensities measured on the negative CSI mass spectra of reline, were related to this potential difference between the so-called Orifice 2 lens and the Ion Guide (see Figure 1). As a result, all the in-source CID experiments have been performed by rising the OR2 voltage value while keeping constant the Orifice 1 voltage value at $30 \mathrm{~V}$. The later is the value for that the sum of ion intensities has been measured at its maximum as the OR 2 voltage was of $5 \mathrm{~V}$ (see Figure S2). By referring to the manufacturer data that indicates that the acting pressure of Ion Guide is close to $1.10^{-3} \mathrm{mbar}$, the collision processes that the reline ions undergo during the crossing of a part of this interface, can be 
compared to the activation regimes occurring in a collision cell such as typically used in CIDMS-MS experiments. It should be noted that the AccuTOF CS mass spectrometer do not allow to performed these ion dissociation experiments after selection of precursor ion. So, from the recorded CSI mass spectra, the intensity of the ions of interest, have been summed at each Orifice 2 voltage value and the contribution of each peak has been reported as a fraction of the total ion intensity. The values of the fractions of the most abundant ions have been reported as a function of the OR2 voltage values and reported in Figure 4.

The graphs reported in Figure 4 indicate that the DES ions integrating two urea molecules are the less stable of the studied ion series under collision activation. Indeed, even though the $\mathrm{m} / \mathrm{z}$ 155 ion $\left[(\mathrm{U})_{2}+\mathrm{Cl}\right]^{-}$stays as the major species detected on the mass spectra, its intensity dramatically decreases as the value of the OR2 voltage is rising. The same trends are observed for the $m / z 453$ and 294 ions but at a lower extend. The $m / z 294$ ion $\left(\left[\mathrm{ChCl}+(\mathrm{U})_{2}+\mathrm{Cl}\right]^{-}\right)$is also the minor ionic species. This reinforces the assumption that this is probably the non-covalent complex formed with the weakest intermolecular interactions of the series plotted in Figure 4. These mass spectrometry results show then that the association of two urea molecules with a cholinium chloride salt, in reline ions do not lead to obtain the most stable ionic non-covalent complex in the gas phase. The reline ions integrating only one urea molecule such as the $\mathrm{m} / \mathrm{z}$ 234 and 373 ions appear slightly more stable than the $m / z 453$ and 294 ions. The proportion of the $m / z 234$ and 373 ions on the CSI mass spectra noticeably increases until a $5 \mathrm{~V}$ value of OR2. This could indicated that these ions would be produced by dissociations of adducts of higher $\mathrm{m} / \mathrm{z}$ ratios. For instance, the loss of urea molecule from the $\mathrm{m} / \mathrm{z}, 453$ and 294 ions under collision activation could produce the $m / z 373$ and 234 ions, respectively. The same interpretation can be proposed for the cholinium chloride anions ( $\mathrm{m} / \mathrm{z}, 174,313$ and 452). Their respective fractions in the mass spectra increase whereas that of all the others is lowered under collision activation as rising the voltage of the Orifice 2. To summarize, the most stable ions in the gas phase appear to be the $\left[(\mathrm{ChCl})_{n}+\mathrm{Cl}\right]^{-}$(where $n=1$ to 3 ) adducts and the addition of urea molecules in the non-covalent complexes is not a favourable parameter to the intrinsic stability of reline gaseous ions.

\subsection{Theoretical study of reline ions}

The conformation, electronic structure and energies of selected $\mathrm{m} / \mathrm{z}$ aggregates have been examined by quantum mechanical calculations. We focused on the lighter ionic clusters detected by CSI-MS (i.e. $\mathrm{m} / z$ 155, 234, 294 and 373). In Figure 5, the most stable geometries 
are represented while the various optimized structures as well as their corresponding energies are given in Tables S1 to S5. Note that the energies of the isolated species that are reported in Table S1, show that interactions between the cholinium cation and the chloride anion, either via the hydroxyl group or the ammonium group, lead to more stable species than the association of $\mathrm{Cl}^{-}$with amino groups of urea.

Looking at the different structures, three general trends on typical interactions between choline, urea and chloride are observed: (i) in agreement with the work of Hunt et al. ${ }^{21}$ the association of urea with chloride occurs via a single chelating urea ${ }^{\cdots} \mathrm{Cl}^{-}$interaction with the formation of two H-bonds except for the dimer $\left[(\mathrm{U})_{2}+\mathrm{Cl}\right]^{-}(\mathrm{m} / \mathrm{z}, 155)$ where the two urea molecules are connected to the chloride via a bidentate interaction, (ii) the cholinium interact preferentially with the chloride anion via the hydrogen of its hydroxy group. A secondary interaction also occurs involving the methyl groups of the choline and thus the formation of three $\mathrm{CH}^{\cdots} \mathrm{Cl}^{-}$ electrostatic interactions. The first interaction is $31.7 \mathrm{~kJ} \mathrm{~mol}^{-1}$ more favourable than the second one. (iii) No clear interaction between urea and cholinium is observed, the most stable conformation always involves structures with direct $[\mathrm{Ch}]^{+\ldots} \mathrm{Cl}^{-}$and urea ${ }^{\cdots} \mathrm{Cl}^{-}$coordinations.

All the structures given in Table S2 to S5 that follow these three tendencies are nearly isoenergetic. A good illustration is, for example, the $\mathrm{m} / \mathrm{z} 234$ anionic cluster, for which we found seven different minima, six of them have less than $9 \mathrm{~kJ} \cdot \mathrm{mol}^{-1}$ difference and follow the three points cited above, while the last one is $60 \mathrm{~kJ} \cdot \mathrm{mol}^{-1}$ higher in energy and shows no bidentate Urea ${ }^{\cdots} \mathrm{Cl}^{-}$interaction but only a single $\mathrm{NH}^{\cdots} \mathrm{Cl}^{-} \mathrm{H}$-bond. Same conclusions can be made for the other $\mathrm{m} / \mathrm{z}$ anionic clusters. Interestingly, we can notice that the molecular organization of the $\mathrm{m} / \mathrm{z} 294$ ion involves the formation of a stabilizing H-bond between the hydroxyl group and the chloride at the expense of the H-bond that an amino group of urea could be establish with this HBA. This agrees with the intrinsic reactivity of the $\mathrm{m} / z, 294$ $\left[\mathrm{ChCl}+(\mathrm{U})_{2}+\mathrm{Cl}\right]^{-}$ion evidenced by CSI-MS under collision activation. The loss of bidentate interaction of the urea with chloride could participate to the dissociation of this $\left[\mathrm{ChCl}+(\mathrm{U})_{2}+\mathrm{Cl}\right]^{-}$ion by loss of an urea molecule, confirming then that this one is a noncovalent ionic assembly among the less stables into the gas-phase. The theoretical study discloses also that the presence of a supplementary urea molecule in the reline ions do not results to a simple attachment of a HBD on an chloride anion initially positioned into the structure, as could be suggest if this was compared to an electrostatic interaction as in the case a cation attachment, e.g. with $\mathrm{Na}^{+}$or $\mathrm{K}^{+}$. If we compare in one hand, the structures of the ions $\mathrm{m} / \mathrm{z}, 234$ and 294 and in other hand, that of the $\mathrm{m} / \mathrm{z} 313$ and 373 ions, it appears that the presence 
of a supplementary urea molecule leads to modify the overall organization of the non-covalent complex. We can also observe from the structures of Figure 5, that the hydrogen bonds maintaining the supramolecular assemblies are no longer the same in the case of the $m / z 294$ and $m / z, 373$ depending on whether we consider two or one urea molecule into the reline ion.

\section{Conclusions}

Cold-spray ionization mass spectrometry can be considered as an analytical method suitable for the determination of the composition in non-covalent complex of a deep eutectic solvent (DES) such as reline. The ions detected on the CSI mass spectra, are characteristic of an association of cholinium chloride salts and urea molecules into a chloride adduct. The interpretation of mass spectrometry observations by the way of the quantum chemical calculation results, describes an organization of the detected gaseous ions, through a maximization of the hydrogen bonds of the DES constituents with the chloride anions. The gas-phase dissociation studies indicate that it is not the increasing number of urea molecules that participate the most to the DES constituent stabilization. Finally, the assembly of two urea molecules with one cholinium chloride salt into a chloride adduct, appears to be the less stable gaseous species under collision activation whereas this supra-molecular organization is considered as the basic structure of the reline formation in condensed phase.

\section{Acknowledgements}

This work was supported by the European Union through the European Regional Development Fund (ERDF), the Ministry of Higher Education and Research, the Région Bretagne, the Département des Côtes d'Armor et d'Ille-et-Vilaine, Rennes Métropole and Saint-Brieuc Armor Agglomération, through the CPER Projects 2015-2020 MATECOM and SOPHIE/STIC \& Ondes. Mass spectrometry analyses were performed on the BioEM ${ }^{2}$ $\left(\mathrm{M}^{2} \mathrm{ARS}\right)$ and Matrix plateformes IETR/Université de Rennes 1. 


\section{REFERENCES}

[1] A. P. Abbott, G. Capper, D. L. Davies, R. K. Rasheed and V. Tambyrajah. Novel Solvent Properties of Choline Chloride/Urea Mixtures. Chem. Commun. 2003, 70-71.

[2] A. Paiva, R. Craveiro, I. Aroso, M. Martins, R. L. Reis and A. R. C. Duarte. Natural Deep Eutectic Solvents - Solvents for the 21st Century. Chem. Eng. 2014, 2, 1063-1071.

[3] Y. Dai, G.-J.Witkamp, R. Verpoorte and Y. H. Choi. Natural Deep Eutectic Solvents as a

New Extraction Media for Phenolic Metabolites in Carthamus Tinctorius L. Anal. Chem. 2013, $85,6272-6278$.

[4] V. Vieira, M. A. Prieto, L. Barros, J. A. P. Coutinho, I. C. F. R. Ferreira and O. Ferreira. Enhanced Extraction of Phenolic Compounds Using Choline Chloride Based Deep Eutectic Solvents from Juglans Regia L. Ind. Crops Prod. 2018, 115, 261-271.

[5] Q. Cui, J.-Z. Liu, L.-T. Wang, Y.-F. Kang, Y. Meng, J. Jiao and Y.-J Fu. Sustainable Deep Eutectic Solvents Preparation and Their Efficiency in Extraction and Enrichment of Main Bioactive Flavonoids from Sea Buckthorn Leaves. J. Clean. Prod. 2018, 184, 826-835.

[6] S. B. Phadtare and G. S. Shankarling. Halogenation Reactions in Biodegradable Solvent: Efficient Bromination of Substituted 1-Aminoanthra-9,10-Quinone in Deep Eutectic Solvent (Choline Chloride : Urea). Green Chem. 2010, 12, 458-462.

[7] B. Singh, H. Lobo and G. Shankarling. Selective N-Alkylation of Aromatic Primary Amines Catalyzed by Bio-Catalyst or Deep Eutectic Solvent. Catal. Lett. 2011, 141, 178-182. [8] J. T. Gorke, F. Srienc, R. J. Kazlauskas, Deep Eutectic Solvents for Candida Antarctica Lipase B-Catalyzed Reactions. In Ionic Liquid Applications: Pharmaceuticals, Therapeutics, and Biotechnology; ACS Symposium Series; American Chemical Society, 2010; Vol. 1038, pp 169-180.

[9] H. Zhao, C. Zhang and T. D. Crittle. Choline-Based Deep Eutectic Solvents for Enzymatic Preparation of Biodiesel from Soybean Oil. J. Mol. Catal. B Enzym. 2013, 85-86, 243-247. [10] Y. Xie, H. Dong, S. Zhang, X. Lu and X. Ji. Solubilities of $\mathrm{CO}_{2}, \mathrm{CH}_{4}, \mathrm{H}_{2}, \mathrm{CO}$ and $\mathrm{N}_{2}$ in Choline Chloride/Urea. Green Energy Environ. 2016, 1, 195-200.

[11] W .C. Su, D. S. H. Wong and M. H. Li. Effect of Water on Solubility of Carbon Dioxide in (Aminomethanamide + 2-Hydroxy-N,N,N-Trimethylethanaminium Chloride). J. Chem. Eng. Data 2009, 54, 1951-1955.

[12] M. Steichen, M. Thomassey, S. Siebentritt and P. J. Dale. Controlled Electrodeposition of $\mathrm{Cu}-\mathrm{Ga}$ from a Deep Eutectic Solvent for Low Cost Fabrication of $\mathrm{CuGaSe}_{2}$ Thin Film Solar Cells. Phys. Chem. Chem. Phys. 2011, 13, 4292-4302. 
[13] A. P. Abbott, G. Capper, K. J. McKenzie, A. Glidle and K. S. Ryder. Electropolishing of

Stainless Steels in a Choline Chloride Based Ionic Liquid: An Electrochemical Study with Surface Characterisation Using SEM and Atomic Force Microscopy. Phys. Chem. Chem. Phys. 2006, 8, 4214-4221.

[14] O. S. Hammond, D. T. Bowron and K. J. Edler. The Effect of Water upon Deep Eutectic Solvent Nanostructure: An Unusual Transition from Ionic Mixture to Aqueous Solution. Angew. Chem. 2017, 129, 9914-9917.

[15] P.L. Pisano, M. Espino, M. de los Á. Fernández, M. F. Silva and A. C. Olivieri. Structural Analysis of Natural Deep Eutectic Solvents. Theoretical and Experimental Study. Microchem. J. 2018, 143, 252-258.

[16] I. Delso, C. Lafuente, J. Munoz-Embid and M. Artal. NMR study of choline-based deep eutectic solvents. J. Mol. Liq. 2019, 290, 111236-111249.

[17] S. L. Perkins, P. Painted and C. M. Colina. Molecular Dynamic Simulations and Vibrational Analysis of an Ionic Liquid Analogue. J. Phys. Chem. B. 2013, 117, 10250-10260. [18] O. S. Hammond, T. D. Bowron and K. J. Edler. Liquid Structure of the Choline ChlorideUrea Deep Eutectic Solvent (Reline) from Neutron Diffraction and Atomistic Modelling. Green Chem. 2016, 18, 2736-2744.

[19] C. F. Araujo, J. A. P. Coutinho, M. M. Nolasco, S. F. Parker, P . J. A. Ribeiro-Claro, S. Rudic, B. I. G. Soares and P. D. Vaz. Inelastic neutron scattering study of reline: shedding light on the hydrogen bonding network of deep eutectic solvents. Phys. Chem. Chem. Phys. 2017, 19, 17998-18009.

[20] S. L. Perkins, P. Painter and C. M. Colina. Experimental and Computational Studies of Choline Chloride-Based Deep Eutectic Solvents. J. Chem. Eng. Data 2014, 59, 3652-3662.

[21] C. R. Ashworth, R. P. Matthews, T. Welton and P. A. Hunt. Doubly ionic hydrogen bond interactions within the choline chloride-urea deep eutectic solvent. Phys. Chem. Chem. Phys. 2016, $18,18145-18160$.

[22] H. Sun, Y. Li, X. Wu and G. Li. Theoretical study in the structures and properties of mixtures of urea and choline chloride. J. Mol. Model. 2013, 19, 2433-2441.

[23] G. Garcia, M. Atilhan and S. Aparicio. An approach for the rationalization of melting temperature for deep eutectic solvents from DFT. Chem. Phys. Lett. 2015, 634, 151-155.

[24] S. Sakamoto, M. Fujita, K. Kim and K. Yamaguchi. Characterization of Self-Assembling Nano-Sized Structures by Means of Coldspray Ionization Mass Spectrometry. Tetrahedron 2000, 56, 955-964. 
[25] K. Yamaguchi. Cold-spray ionization mass spectrometry: principle and applications. $J$. Mass Spectrom. 2003, 38, 473-490.

[26] K. Yamaguchi. Cold-Spray Ionization Mass Spectrometry: Applications in Structural Coordination Chemistry. J. Mass Spectrom. Soc. Japan 2013, 2, 1-7.

[27] S. Sakamoto, M. Yoshizawa, T. Kusukawa, M. Fujita, K. Ya-maguchi. Characterization of Encapsulating Supramolecules by Using CSI-MS with Ionization-Promoting Reagents. Org. Lett. 2001, 3, 1601-4604.

[28] E.F. Wilson, H. Abbas, B.J. Duncombe, C. Streb, D.-L. Long and L. Cronin. Probing the Self-Assembly of Inorganic Cluster Architectures in Solution with Cryospray Mass Spectrometry: Growth of Polyoxomolybdate Clusters and Polymers Mediated by Silver(I) Ions. J. Am. Chem. Soc. 2008, 130, 13876-13884.

[29] H.N. Miras, E. Wilson and L. Cronin. Unravelling the complexities of inorganic and supramolecular self-assembly in solution with electrospray and cryospray mass spectrometry. Chem. Commun. 2009, 1297-1311.

[30] S. Sakamoto, T. Imamoto and K. Yamaguchi. Characterization of Encapsulating Supramolecules by Using CSI-MS with Ionization-Promoting Reagents. Org. Lett. 2001, 3, 1793-1795.

[31] S. Sakamoto and K. Yamaguchi. Hyperstranded DNA Architectures Observed by ColdSpray Ionization Mass Spectrometry. Angew. Chem., Int. Ed. Engl. 2003, 4, 905-908.

[32] K. Ohara and K. Yamaguchi. Cold-Spray Ionization Mass Spectrometric Detection of a Coordination Oligomer. Anal. Sci. 2012, 28, 635-637.

[33] K. Ohara, M. Tominaga, I. Azumaya, K. Yamaguchi. Solvent-dependent Assembly of Discrete and Continuous CoCl2 Adamantane-based Ligand Complexes: Observations by CSIMass Spectrometry and X-ray Crystallography. Anal. Sci. 2013, 29, 773-776.

[34] K. Ohara, M. Tominaga, H. Masu, I. Azumaya and K. Yamaguchi. Adamantane-based bidendate metal complexes in crystalline and solution state. Anal. Sci. 2016, 32, 1347-1352.

[35] K. Shikii, S. Sakamoto, H. Seki, H. Utsumi and K. Yamaguchi. Narcissistic aggregation of steroid compounds in diluted solution elucidated by CSI-MS, PFG NMR and X-ray analysis. Tetrahedron 2004, 60, 3487-3492.

[36] M.J. Frisch, G. W. Trucks, H.B. Schlegel, G. E. Scuseria, M. A. Robb, J. R. Cheeseman, G. Scalmani, V. Barone, B. Mennucci, G. A. Petersson, H. Nakatsuji, M. Caricato, X. Li, H. P. Hratchian, A. F. Izmaylov, J. Bloino, G. Zheng, J. L. Sonnenberg, M. Hada, M. Ehara, K. Toyota, R. Fukuda, J. Hasegawa, M. Ishida, T. Nakajima, Y. Honda, O. Kitao, H. Nakai, T. Vreven, J. A. J. Montgomery, J. E. Peralta, F. Ogliaro, M. Bearpark, J. J. Heyd, E. Brothers, 
K. N. Kudin, V. N. Staroverov, R. Kobayashi, J. Normand, K. Raghavachari, A. Rendell, J. C. Burant, S. S. Iyengar, J. Tomasi, M. Cossi, N. Rega, J. M. Millam, M. Klene, J. E. Knox, J. B. Cross, V. Bakken, C. Adamo, J. Jaramillo, R. Gomperts, R. E. Stratmann, O. Yazyev, A. J. Austin, R. Cammi, C. Pomelli, J. W. Ochterski, R. L. Martin, K. Morokuma, V. G. Zakrzewski, G. A. Voth, P. Salvador, J. J. Dannenberg, S. Dapprich, A. D. Daniels, Ö. Farkas, J. B. Foresman, J. V. Ortiz, J. Cioslowski and D. J. Fox, Gaussian 09 Rev. D.01, Wallingford, CT, 2016.

[37] A. D. Becke. Density-functional thermochemistry. III. The role of exact exchange. $J$. Chem. Phys. 1993, 98, 5648-5652.

[38] S. Grimme, J. Antony, S. Ehrlich and H. Krieg. A consistent and accurate ab initio parametrization of density functional dispersion correction (DFT-D) for the 94 elements $\mathrm{H}-\mathrm{Pu}$. J. Chem. Phys. 2010, 132, 154104-154119.

[39] D. A. Case, I. Y. Ben-Shalom, S. R. Brozell, D. S. Cerutti, T. E. I. Cheatham, V. W. D. Cruzeiro, T. A. Darden, R. E. Duke, D. Ghoreishi, M. K. Gilson, H. Gohlke, A. W. Goetz, D. Greene, R. Harris, N. Homeyer, S. Izadi, A. Kovalenko, T. Kurtzman, T. S. Lee, S. LeGrand, P. Li, C. Lin, J. Liu, T. Luchko, R. Luo, D. J. Mermelstein, K. M. Merz, Y. Miao, G. Monard, C. Nguyen, H. Nguyen, I. Omeylan, A. Onufriev, F. Pan, R. Qi, D. R. Roe, A. Roitberg, C. Sagui, S. Schott-Verdugo, J. Shen, C. L. Simmerling, J. Smith, R. Salomon-Ferrer, J. Swails, R. C. Walker, J. Wang, H. Wei, R. M. Wolf, W. X., L. Xiao, D. York and P. A. Kollman. AMBER 2018, University of California, San Francisco: 2019.

[40] J. Wang, R. M. Wolf, J. W. Caldwell, P. A. Kollmann and D. A. Case. Development and testing of a general AMBER force field. J. Comput. Chem. 2004, 25, 1157-1174.

[41] J. A. Loo. Electrospray ionization mass spectrometry: a technology for studying noncovalent macromolecular complexes. Int. J. Mass Spectrom. 2000, 200, 175-186.

[42] P. Kebarle and U. H. Verkerk. Electrospray: From ions in solution to ions in the gas phase, what we know now. Mass Spectrom. Rev. 2009, 28, 898-917. 
TABLE 1. Results of Accurate Mass Measurements performed from the ESI mass spectrum of reline.

\begin{tabular}{c}
\hline$m / z$ \\
\begin{tabular}{|c|c|c|c|}
\hline 174.0452 & $\mathrm{C}_{5} \mathrm{H}_{14} \mathrm{NOCl}_{2}$ & $174.0452(0)$ & 1 \\
\hline 313.1202 & $\mathrm{C}_{10} \mathrm{H}_{28} \mathrm{~N}_{2} \mathrm{O}_{2} \mathrm{Cl}_{3}$ & $313.1216(-4.5)$ & 2 \\
\hline 452.2000 & $\mathrm{C}_{15} \mathrm{H}_{42} \mathrm{~N}_{3} \mathrm{O}_{3} \mathrm{Cl}_{4}$ & $452.1980(4.1)$ & 3 \\
\hline 591.2733 & $\mathrm{C}_{20} \mathrm{H}_{56} \mathrm{~N}_{4} \mathrm{O}_{4} \mathrm{Cl}_{5}$ & $591.2744(-1.1)$ & 4 \\
\hline 730.3493 & $\mathrm{C}_{25} \mathrm{H}_{70} \mathrm{~N}_{5} \mathrm{O}_{5} \mathrm{Cl}_{6}$ & $730.3468(2.5)$ & 5 \\
\hline 869.4313 & $\mathrm{C}_{30} \mathrm{H}_{84} \mathrm{~N}_{6} \mathrm{O}_{6} \mathrm{Cl}_{7}$ & $869.4272(4.1)$ & 6 \\
\hline 1008.4970 & $\mathrm{C}_{35} \mathrm{H}_{98} \mathrm{~N}_{7} \mathrm{O}_{7} \mathrm{Cl}_{8}$ & $1008.5036(6.0)$ & 7 \\
\hline
\end{tabular}
\end{tabular}


TABLE 2. Results of Accurate Mass Measurements performed from the CSI mass spectrum of reline.

\begin{tabular}{|c|c|c|c|}
\hline$m / z$ & Proposed formula & $\begin{array}{c}\text { Calculated mass } \\
\text { (error in ppm) }\end{array}$ & $\begin{array}{c}\text { Choline } \\
\text { chloride : Urea }\end{array}$ \\
\hline 95.0015 & $\mathrm{CH}_{4} \mathrm{~N}_{2} \mathrm{OCl}$ & $95.00122(2.8)$ & $0: 1$ \\
\hline 155.0336 & $\mathrm{C}_{2} \mathrm{H}_{8} \mathrm{~N}_{4} \mathrm{O}_{2} \mathrm{Cl}$ & $155.0336(0)$ & $0: 2$ \\
\hline 215.0664 & $\mathrm{C}_{3} \mathrm{H}_{12} \mathrm{~N}_{6} \mathrm{O}_{3} \mathrm{Cl}$ & $215.0659(2.0)$ & $0: 3$ \\
\hline 234.0867 & $\mathrm{C}_{6} \mathrm{H}_{18} \mathrm{~N}_{3} \mathrm{O}_{2} \mathrm{Cl}_{2}$ & $234.0776(-1.4)$ & $1: 1$ \\
\hline 294.1113 & $\mathrm{C}_{7} \mathrm{H}_{22} \mathrm{~N}_{5} \mathrm{O}_{3} \mathrm{Cl}_{2}$ & $294.1010(4.5)$ & $1: 2$ \\
\hline 354.1458 & $\mathrm{C}_{8} \mathrm{H}_{26} \mathrm{~N}_{7} \mathrm{O}_{4} \mathrm{Cl}_{2}$ & $354.1423(8.9)$ & $1: 3$ \\
\hline 373.1531 & $\mathrm{C}_{11} \mathrm{H}_{32} \mathrm{~N}_{4} \mathrm{O}_{3} \mathrm{Cl}_{3}$ & $373.1540(-2.4)$ & $2: 1$ \\
\hline 433.1865 & $\mathrm{C}_{12} \mathrm{H}_{36} \mathrm{~N}_{6} \mathrm{O}_{4} \mathrm{Cl}_{3}$ & $433.1864(0.4)$ & $2: 2$ \\
\hline 493.2222 & $\mathrm{C}_{13} \mathrm{H}_{40} \mathrm{~N}_{8} \mathrm{O}_{5} \mathrm{Cl}_{3}$ & $493.2190(7.0)$ & $2: 3$ \\
\hline 512.2305 & $\mathrm{C}_{16} \mathrm{H}_{46} \mathrm{~N}_{5} \mathrm{O}_{4} \mathrm{Cl}_{4}$ & $512.2304(0.3)$ & $3: 1$ \\
\hline 572.2626 & $\mathrm{C}_{17} \mathrm{H}_{50} \mathrm{~N}_{7} \mathrm{O}_{5} \mathrm{Cl}_{4}$ & $572.2627(0.2)$ & $3: 2$ \\
\hline 632.2925 & $\mathrm{C}_{18} \mathrm{H}_{54} \mathrm{~N}_{9} \mathrm{O}_{6} \mathrm{Cl}_{4}$ & $632.2951(-4.1)$ & $3: 3$ \\
\hline 651.3036 & $\mathrm{C}_{21} \mathrm{H}_{60} \mathrm{~N}_{6} \mathrm{O}_{5} \mathrm{Cl}_{5}$ & $651.3068(-4.9)$ & $4: 1$ \\
\hline 692.3256 & $\mathrm{C}_{19} \mathrm{H}_{58} \mathrm{~N}_{11} \mathrm{O}_{7} \mathrm{Cl}_{4}$ & $692.3275(-2.7)$ & $3: 4$ \\
\hline
\end{tabular}




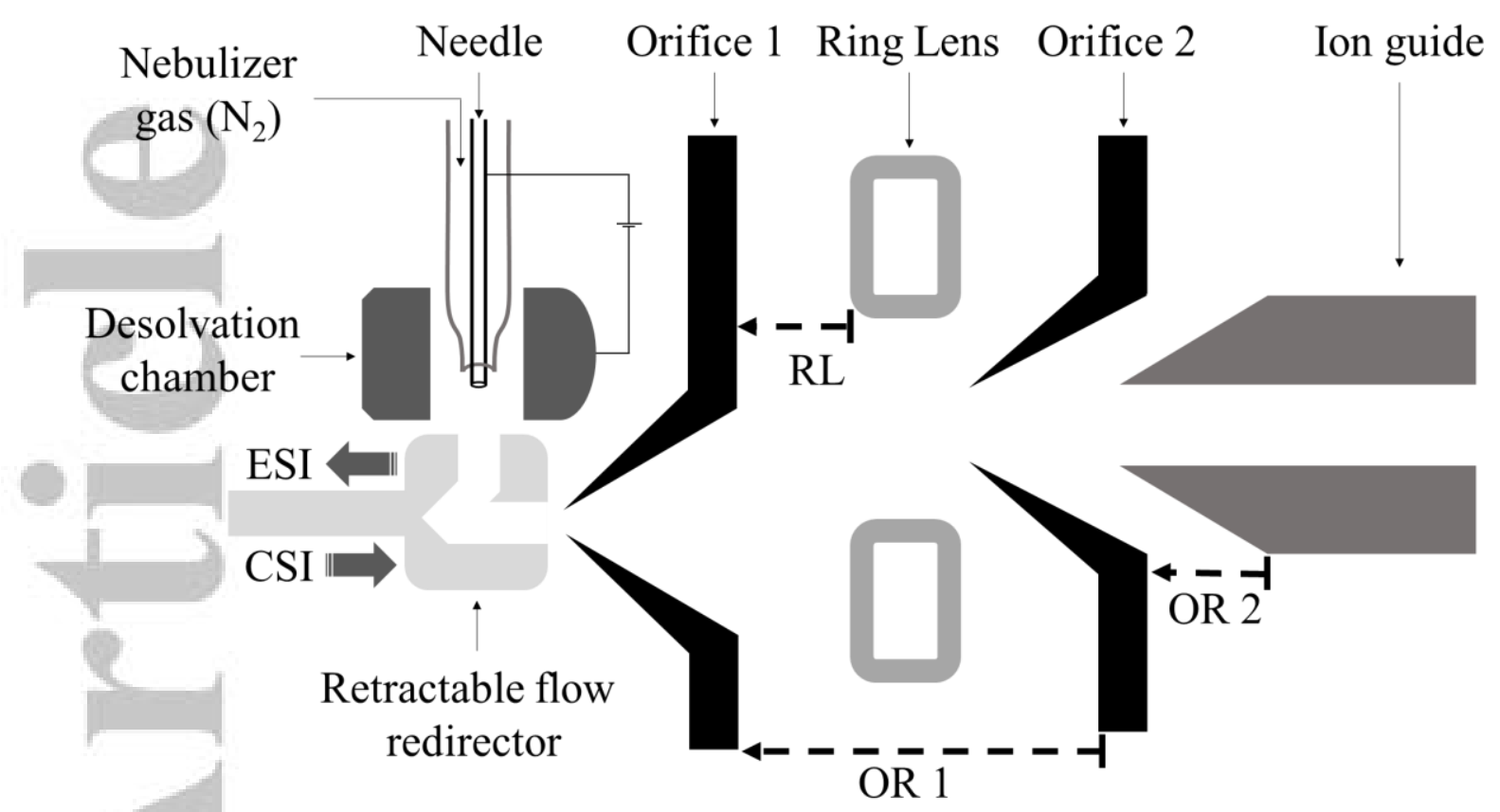

FIGURE 1: Dual source ESI/CSI of the AccuTOF CS mass spectrometer. Note that the change of electrospray ionization (ESI) for the cold-spray ionization (CSI) is ensured by the used of liquid nitrogen cooling device (not shown in the figure) for the desolvation gas and the positioning of the retractable flow redirector between the desolvation chamber and the Orifice 1 lens entrance. 

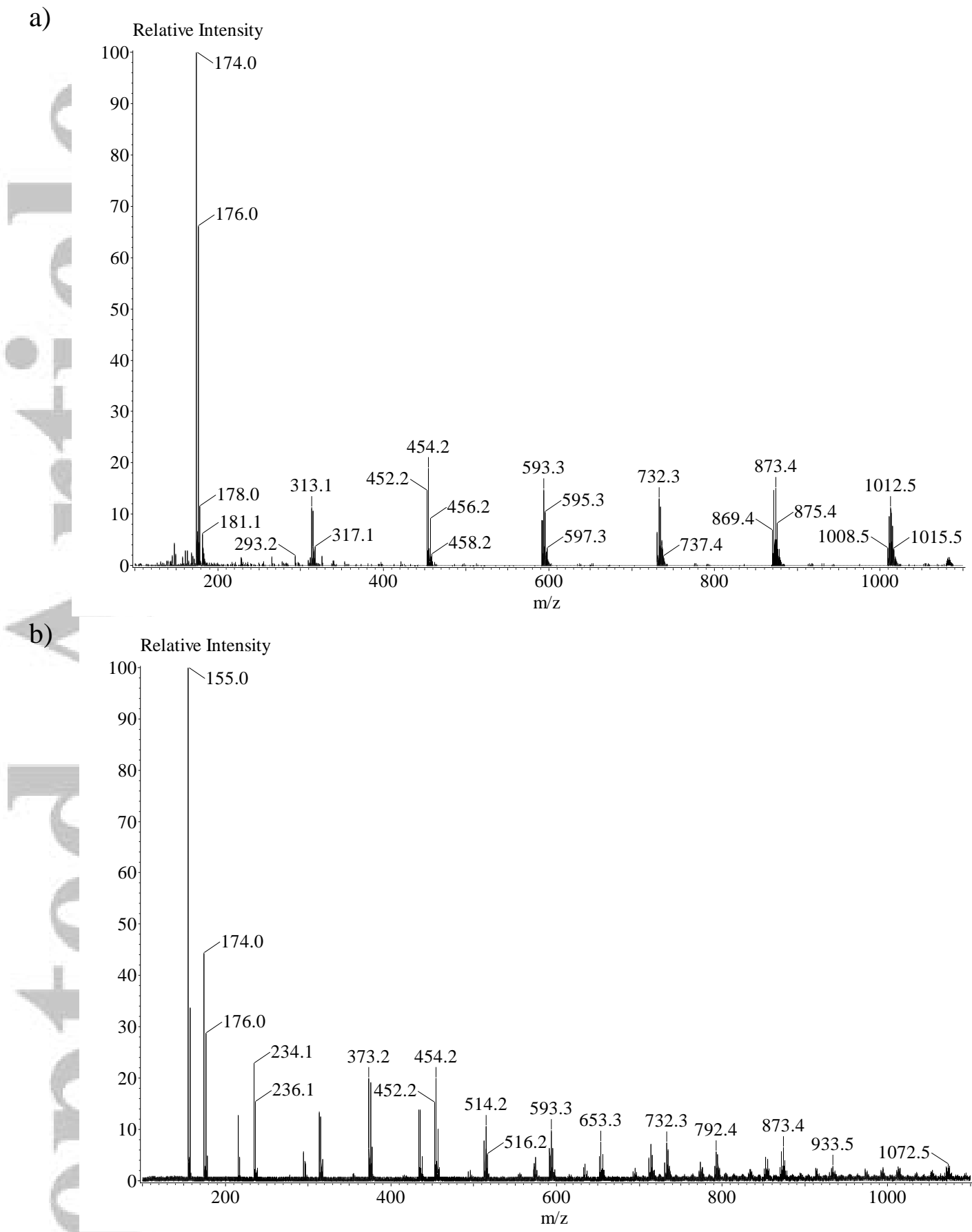

FIGURE 2. Comparison of a) ESI(-) and b) CSI (Spray and capillary temperatures fixed at $-30{ }^{\circ} \mathrm{C}$ ) mass spectra of reline. 


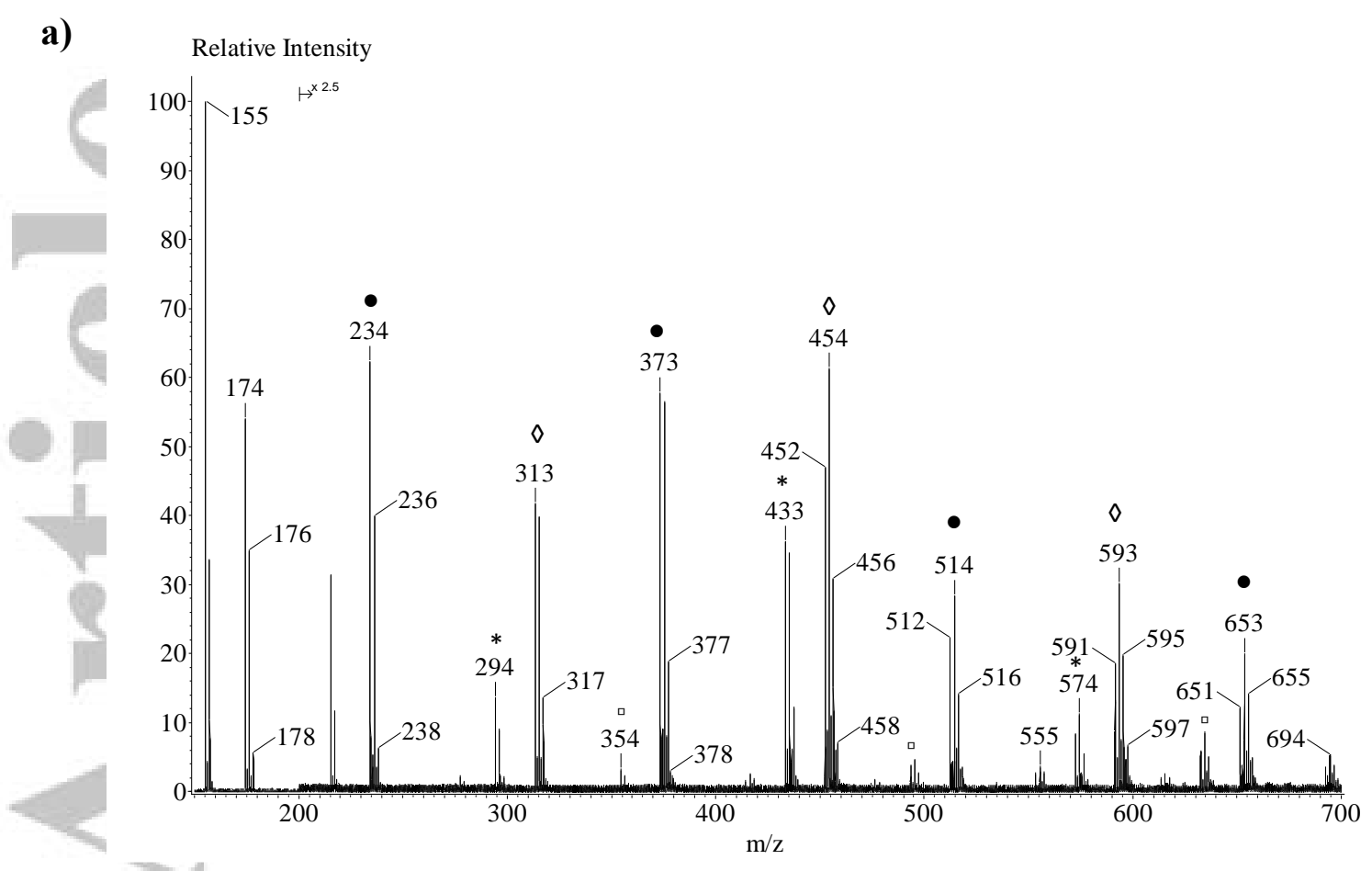

b) Relative Intensity

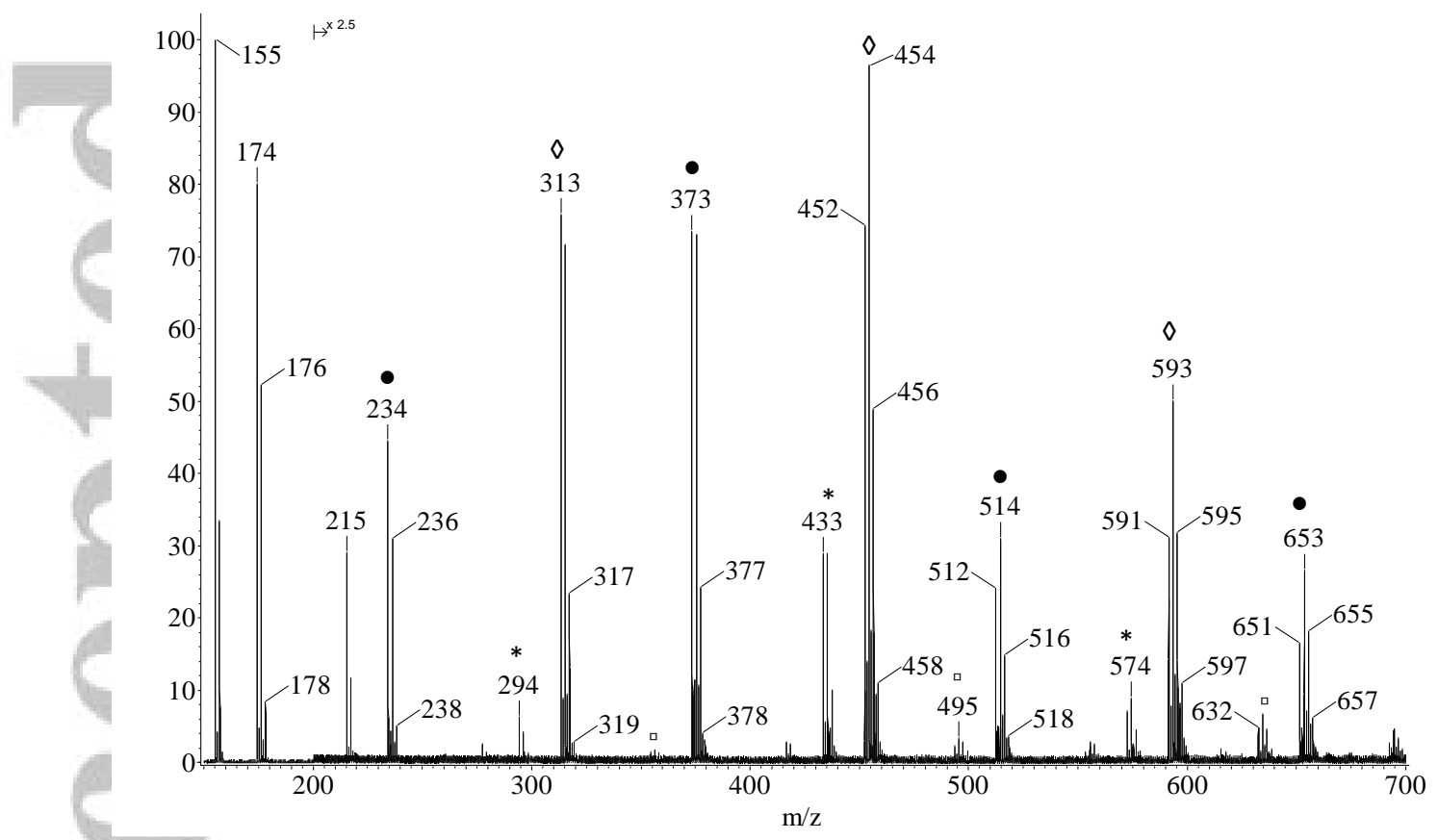

FIGURE 3. CSI(-) mass spectra of reline sample in acetonitrile at a nebulizing gas temperature of a) $-40^{\circ} \mathrm{C}$ and b) $0^{\circ} \mathrm{C}$, where the symbols $(\diamond),(\bullet),\left(^{*}\right)$, and ( $\left.{ }^{\circ}\right)$ indicate the ion populations that can be written such as: $\left[(\mathrm{ChCl})_{n}+\mathrm{Cl}\right]^{-},\left[(\mathrm{ChCl})_{n}+\mathrm{U}+\mathrm{Cl}\right]^{-},\left[(\mathrm{ChCl})_{n}+(\mathrm{U})_{2}+\mathrm{Cl}\right]^{-}$, $\left[(\mathrm{ChCl})_{n}+(\mathrm{U})_{3}+\mathrm{Cl}\right]^{-}$, respectively, and where $n$ ranges from 1 to 4. 

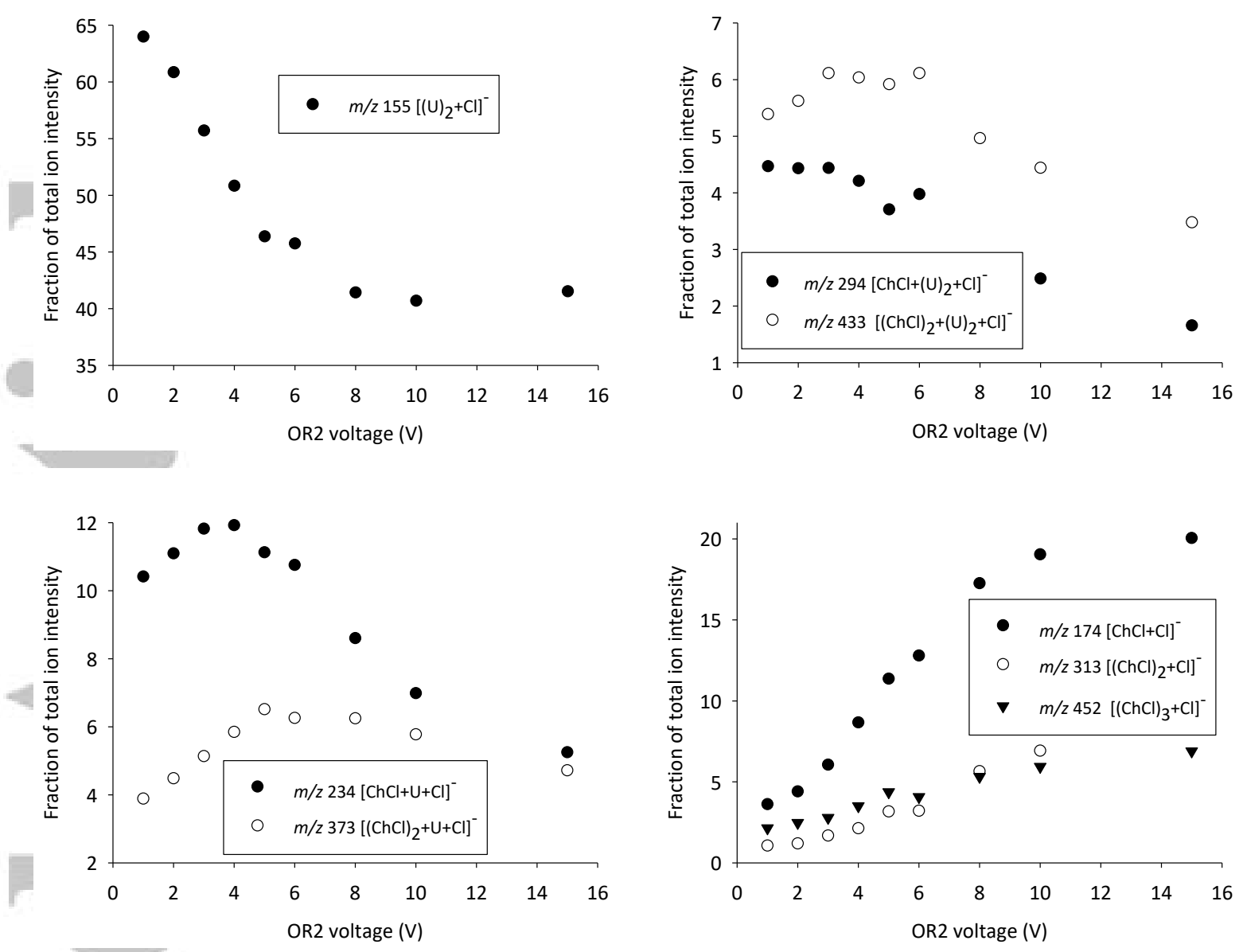

FIGURE 4. Fractions of intensities of the ions $\left[(\mathrm{U})_{2}+\mathrm{Cl}\right]^{-},\left[(\mathrm{ChCl})_{n}+(\mathrm{U})_{2}+\mathrm{Cl}\right]^{-}$, $\left[(\mathrm{ChCl})_{n}+\mathrm{U}+\mathrm{Cl}\right]^{-}$and $\left[(\mathrm{ChCl})_{n}+\mathrm{Cl}\right]^{-}$, and where $n=1$ to 3 reported as a function of the orifice 2 voltage values. 


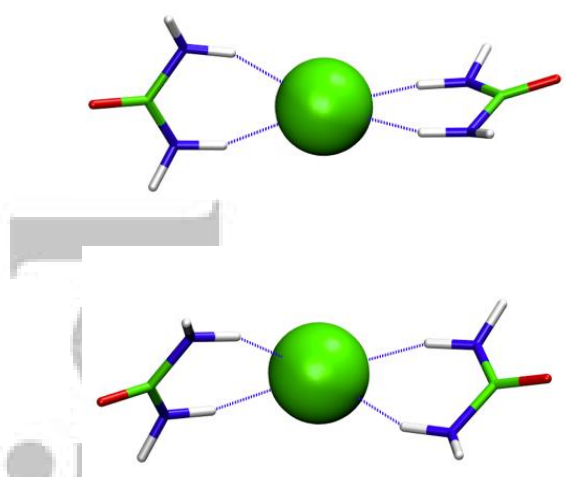

$\mathrm{m} / \mathrm{z} 155$

$\left[(\mathrm{U})_{2}+\mathrm{Cl}\right]$

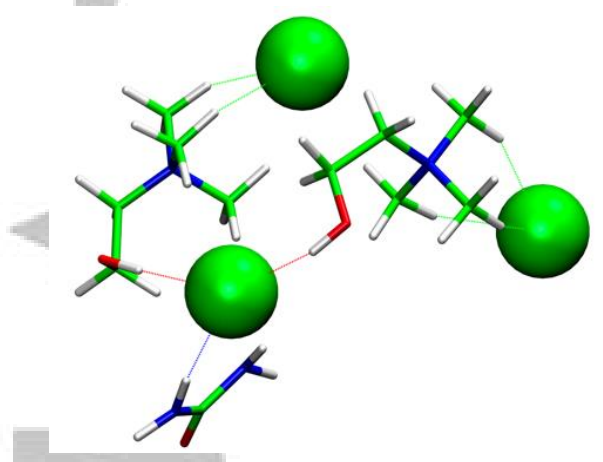

$\mathrm{m} / \mathrm{z} 373$

$\left[(\mathrm{ChCl})_{2}+\mathrm{U}+\mathrm{Cl}\right]^{-}$

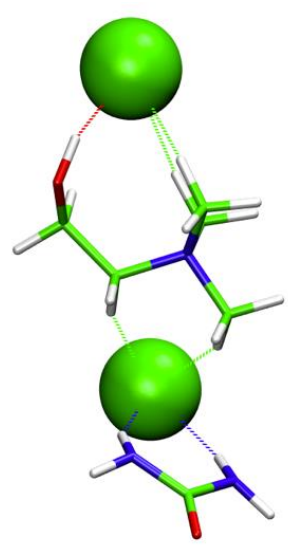

$m / z 234$

$[\mathrm{ChCl}+\mathrm{U}+\mathrm{Cl}]$

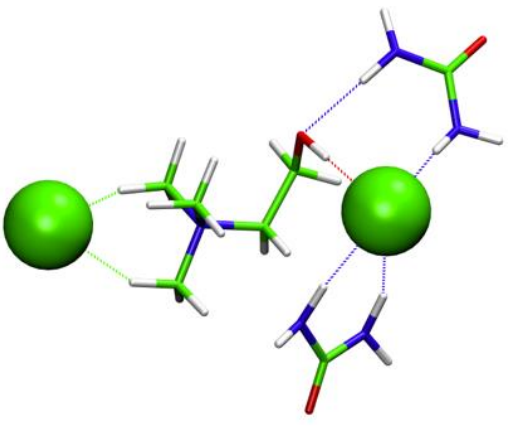

$m / z 294$

$\left[\mathrm{ChCl}+(\mathrm{U})_{2}+\mathrm{Cl}\right]$

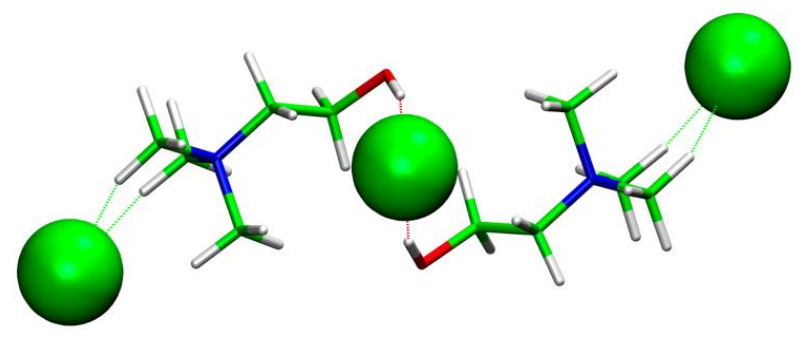

$\mathrm{m} / \mathrm{z} 313$

$\left[(\mathrm{ChCl})_{2}+\mathrm{Cl}\right]$

FIGURE 5. Snapshots of the most stable structures of the $\mathrm{m} / \mathrm{z}$ ions $(\mathrm{m} / \mathrm{z}$ from 155 to 373) obtained after QME(B3LYP/6-311++G(d,p) geometry optimization. For the energies see Table S1 to S5. 


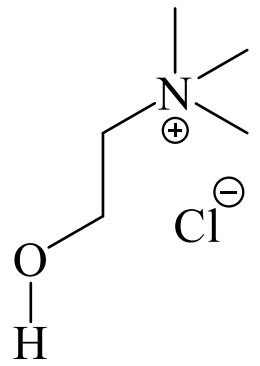

Cholinium chloride salt $(\mathrm{ChCl})$<smiles>NC(N)=O</smiles>

Urea molecule (U)

Scheme 1: Chemical structures of compounds forming the Reline as Deep Eutectic Solvent

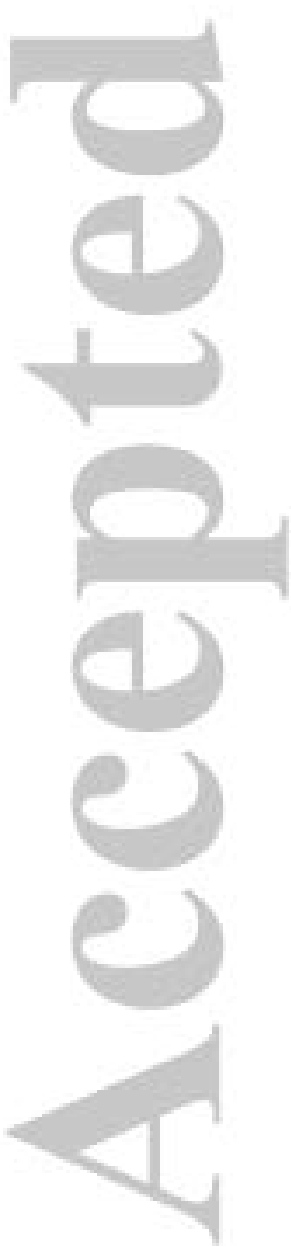

